\title{
STRUCTURAL PROPERTIES OF THE COMBINING SITE OF ANTI STREPTOCOCCUS GROUP A ANTIBODIES: SPIN LABEL-HAPTEN STUDIES
}

\author{
by \\ FLEMMING M. POULSEN \\ and \\ JACK T. JOHANSEN \\ Department of Chemistry, Carlsberg Laboratory \\ Gamle Carlsberg Vej 10, DK-2500 Copenhagen, Valby \\ and \\ JENS A. PEDERSEN \\ Institute of Chemistry, University of Árhus, \\ Langelandsgade 150, DK-8000 Ȧrhus C
}

Keywords: Antibodies, Gd(III)-binding sites, N-acetyl-glucosamine, spin-labels, e.s.r.-spectroscopy

The size of the combining site of anti Streptococcus group A antibodies has been examined by a set of spin labelhaptens. The results indicate that the examined combining site has a structure large enough to envelop two glucopyranose rings. Furthermore it appears that the combining site cannot accomodate the branching residues of the polysaccharide antigen.

The interaction between the lanthanide (III) ion and the hapten combining sites of anti streptococcal antibodies has been examined by e.s.r.-spectroscopy. It was demonstrated that the antagonistic interaction between the two sites previously observed in the myeloma protein MOPC 315 (DWEK et al., Biochem. J. 155, 37-53 (1976)), was also characteristic of the anti Streptococcus antibodies. The findings suggest that the antagonism between the two binding sites is a general feature of antibodies.

\section{INTRODUCTION}

The study of antibody combining sites employing paramagnetic compounds was initiated by STRYER \& GRIFFITH (13), who studied the combining site of anti-DNP antibodies using paramagnetic nitroxide free radicals as spin labels attached to the hapien DNP. Later Hsia \& PietTe determined the size of an anti-DNP-antibody combining site employing a set of DNP-spin label derivatives with the spin labels attached to the hapten by spacer groups of different length (4). Recently 
DWEK et al. (1) showed that the paramagnetic ions of the lanthanide series bind to normal rabbit IgG at six binding sites, one in each of the six subglobular fractions of the $\operatorname{IgG}$ molecule. Furthermore they demonstrated that the binding site of $\mathrm{Gd}(\mathrm{III})$ is very close to the combining site of the Fv-fragment of the DNPbinding myeloma protein MOPC-315 (2). Thus the paramagnetic ions of the lanthanide series can be applied as paramagnetic probes for studying the combining sites of naturally occuring antibodies. DWEK et al. (2) found that the mutual binding of the metal and the hapten was determined by an antagonistic mechanism, which would reduce the binding of hapten in the presence of metal and vice versa.

In the present work we have studied the binding of site specific hapten spin label derivatives to anti Streptococcus group A antibodies, as well as the effect of $\mathrm{Gd}(\mathrm{III})$ on this binding. We have demonstrated, that the anti Streptococcus group A antibodies*) are similar to the myeloma proteins with respect to the effect of Gd(III) on the binding of hapten. To probe the size of the combining site of these antibodies, we have synthesized a set of hapten spin label compounds, structurally similar to the immunogenic residues of the cell wall polysaccharide of group A Streptococci. From the e.s.r. spectra of these carbohydrate spin labels bound to the combining sites of antibodies it is concluded that the combining site has a size, capable of accomodating two pyranose rings of the cell wall polysaccharide.

\section{MATERIALS AND METHODS}

\subsection{Anti Streptococcus group A antisera}

These sera were obtained from rabbits hyperimmunized with a group A streptococcal vaccine (11). The antibodies were isolated from the sera employing an immunoadsorbent of $\mathrm{N}$-acetylglucosamine (NAG) coupled to Sepharose through a spacer arm of glycyltyrosyl-azo-phenyl (11). After application of the serum, the column was washed with phosphate buffer $\mathrm{pH}$ 7.4. The adsorbed antibodies were eluted from the immunoadsorbent using $1 \mathrm{M}$ propionic acid. The fractions containing protein were extensively dialyzed against water and subsequently lyophilized. Antibodies were partially digested with papain employing the method of PORTER (10). The Fab fragments were purified by affinity chromatography using the NAG-Sepharose immunoadsorbent. The spin label-hapten molecules 3-carboxamido- $\mathrm{N}$ p(-[acetamido-2-deoxy- $\beta$, D-glycopyranoside]phenyl)-2, 2, 5, 5-tetramethyl-3-pyrroline-1-oxyl (Figure 1 [I]) and 3-carboxamido-N-(o-[2acetamido-2-deoxy- $\beta$, D-glucopyranoside]-phenyl)-2, 2, 5, 5-tetramethyl-2-pyrrolidine-1-oxyl (Figure 1 [II]) were prepared as described in section 2.3.

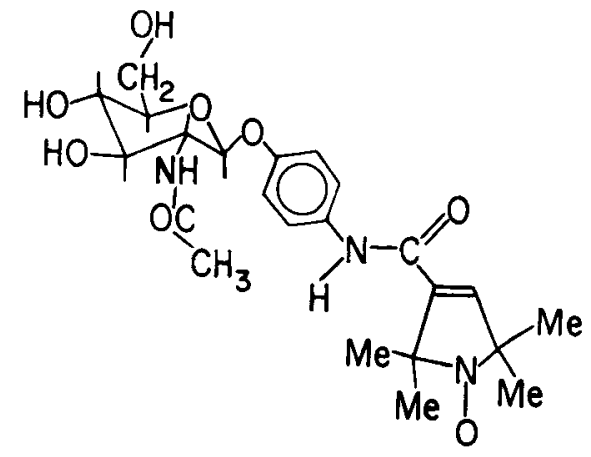

[1]

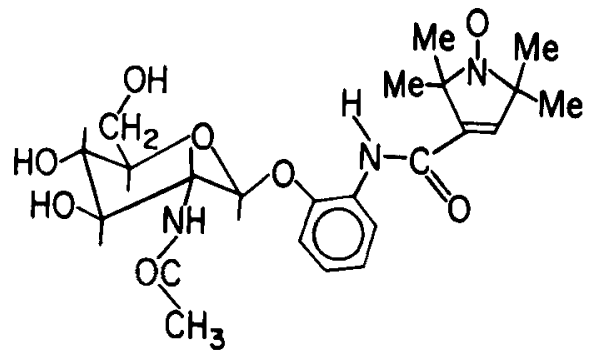

[II]

Figure 1. Structure of the synthesized NAG-spin labels.

E.s.r. measurements were performed at $21^{\circ} \mathrm{C}$ on a Varian E-3 e.s.r. spectrometer operating at the X-band $(9.25 \mathrm{GHz})$. Spin label titrations

*) Unless quoted, the word antibodies shall be used throughout this paper synonomously with anti Streptococcus group $\mathrm{A}$ antibodies. 
were performed as dilution experiments. Solutions containing Fab fragments and spin labels were diluted with spin label, maintaining the concentration of spin label at $50 \mu \mathrm{M}$. After each dilution e.s.r. measurements were performed on $50 \mu 1$ Fab solutions contained in a capillary syringe, used directly as a sample cell. Solutions of gadolinium chloride were prepared from anhydrous gadolinium oxide and concentrated hydrochloric acid.

\subsection{Interpretation of e.s.r. spectra}

The paramagnetic resonance spectrum of nitroxide free radicals arises from allowed transitions between the eigenstates of the Hamiltonian

$$
\mathscr{H}=|\beta| \mathrm{S} \cdot \mathrm{g} \cdot \mathrm{H}+\mathrm{h} \cdot \mathrm{S} \cdot \mathrm{A} \cdot \mathrm{I}-\mathrm{g}_{\mathrm{N}} \beta_{\mathrm{N}} \cdot \mathrm{I} \cdot \mathrm{H}
$$

where $g$ is the tensor of the $g$ factor and $A$ the nuclear hyperfine tensor. $H$ is the applied field, $\beta$ and $\beta_{N}$ the electron and nuclear Bohr magnetons, h Planck's constant and S and I the electron and nuclear spin angular momentum operators in units of $\hbar$. The principal values of the $g$ and the $A$ tensor along the axis of a Cartesian coordinate system, in which the $x$-axis is along the $\mathrm{N}-\mathrm{O}$ bond and the z-axis perpendicular to this along the odd $2 \mathrm{p} \pi$-orbital, are $g_{x x}, g_{y y}, g_{z z}$, and $A_{x x}, A_{y y}, A_{z z}$. The magnitudes of these are usually obtained from e.s.r. studies of free radicals incorporated in host crystals (5). The outer splitting of spectra obtained from such studies is correlated to the principal values of the hyperfine splittings by the equation

$$
A_{D}=\left(A_{x x}^{2} \cdot \sin ^{2} D+A_{z z}^{2} \cdot \cos ^{2} D\right)^{1 / 2}
$$

where $D$ is the angle between the $z$-axis and the magnetic field direction. The magnitudes for $A_{x x}, A_{y y}, A_{z z}$ are thus equal to the outer splitting, when the magnetic field is directed along the respective axis. For nitroxide free radicals these values are approximately $A_{x x}=$ $A_{y y}=6 G$ and $A_{z z}=32 G$ (5). When nitroxide free radicals are randomly oriented and perform rapid isotropic motions, the principal splitting constants and g-factors are averaged and a sharp three line spectrum is obtained. This spectrum is characterized by the isotropic values $g_{0}=1 / 3\left(g_{x x}+g_{y y}+g_{z z}\right)$ and $a_{0}=1 / 3\left(A_{x x}\right.$ $\left.+A_{y y}+A_{z z}\right)$. When motions of the nitroxide are anisotropic and/or slow, motional averaging becomes incomplete and the hyperfine splittings as well as the g-factor will depend on the amplitude and the rate of the motion.

\subsection{Spin-label derivatives}

o- and p-aminophenyl-tetraacetyl-glucoseaminid were prepared starting from $\mathrm{N}$-acetylglucosamine $(3,9,12,14)$. All nitroxyl spin labels were synthesized by the methods of ROZANTZEV, starting from ammonia and acetone (12).

\subsubsection{3-carboxamido-N (p-(2-acetamido-2-deoxy-}

$\beta, D$-glucopyranosid)-phenyl) 2, 2, 5, 5tetramethyl-3-pyrroline-1-oxyl

5 mmol of 3-carboxy-2, 2, 5, 5-tetramethyl-3pyrroline-1-oxyl were dissolved in $20 \mathrm{ml}$ of dry benzene and $0.6 \mathrm{ml}$ of dry pyridine, and $5 \mathrm{mmol}$ of thionylchloride were added. The reaction mixture was left for one hour and then filtered. The filtrate was added to a solution of $4.5 \mathrm{mmol}$ of 1-(p-aminophenyl)-3, 4, 6-triacetyl-2-acetamido-2-deoxy- $\beta$, D-glucopyranosid in $5 \mathrm{ml}$ of chloroform and $0.5 \mathrm{ml}$ of dry pyridine. After one hour the solvents were evaporated and the residue redissolved in chloroform. The chloroform solution was washed succesively with 10\% hydrochloric acid, 2 M-sodium hydroxide and finally with water. After drying over sodium sulphate, the chloroform was evaporated. The residue was dissolved in ether and crystallized upon addition of petrolether. This paramagnetic compound [I] (Figure 1) was pure, according to thin layer chromatography. The product was deacetylated in anhydrous methanol by catalytic amounts of freshly prepared sodium methoxide. When all material was deacetylated, as judged by thin layer chromatography, it was isolated by evaporation of the solvent and redissolved in water, from which it crystallized. mp. $243-45^{\circ} \mathrm{C}$. Found: C, 55.3; H, 6.9; N, 8.5. Calculated: C, 55.6; H, 6.9: $\mathrm{N}, 8.4$, assuming one mole of water of crystallization.

The corresponding ortho compound [II] (Figure 1) was synthesized by the same procedure as described for the para compound. In this case, however, traces of sodium ions were removed from the final product by passing 
a solution of the compound through a column of Dowex $50 \times 4$ ion exchange resin. The eluate was lyophilized to give [II] $\mathrm{mp} .169-169^{\circ} \mathrm{C}$. Found: C 54.7; H, 6.9; N, 8.3. Calculated: C, $54.7 ; \mathrm{H}, 6.9 ; \mathrm{N}, 8.3$, assuming 1.5 molecules of water of crystallization.

\section{RESULTS AND DISCUSSION}

\subsection{Motions of the spin label haptens I and II}

Anchored to the antibody combining site by the NAG part of the spin label hapten molecule, the nitroxide group is restricted to the international motions of the hapten molecule, and to the imposed motion of the protein. Since the correlation time of the motion of the latter is relatively long, this motion does not contribute to average the hyperfine splitting constants of the nitroxide group. Thus on the time scale of e.s.r. spectroscopy the motion of the nitroxide group of the anchored spin label hapten molecule is primarily defined by the intramolecular motions of the pyrroline ring. Such motions most likely originate from rotations around single bonds in the spin label molecule. The molecules I and II (Figure I)

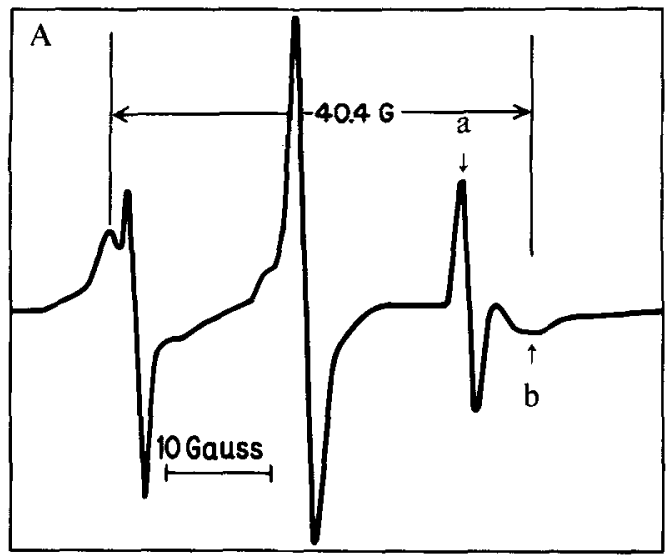

Figure 2. E.s.r.-spectra of equilibrium mixtures of spin label hapten and anti Streptococcus group A antibodies Fab-fragments. A) Hapten 1: The sample was $1 \mathrm{~mm}-F a b, 50 \mu \mathrm{m}$-hapten, $0.01 \mathrm{M}$-MES, $0.05 \mathrm{M}$ $\mathrm{NaCl}, \mathrm{pH} 6.79$. B) Hapten II: The sample was $1.7 \mathrm{mM}$ Fab. $50 \mu \mathrm{M}$-hapten, 0.01 M-MES; $0.15 \mathrm{M}-\mathrm{NaCl}$, pH 6.79. The fractions of free spin label in $A$ and $B$ are $17 \%$ and $70 \%$ respectively. The vertical bars indicate the outer splitting which are $40.4 \mathrm{G}$ and $49.6 \mathrm{G}$, respectively.

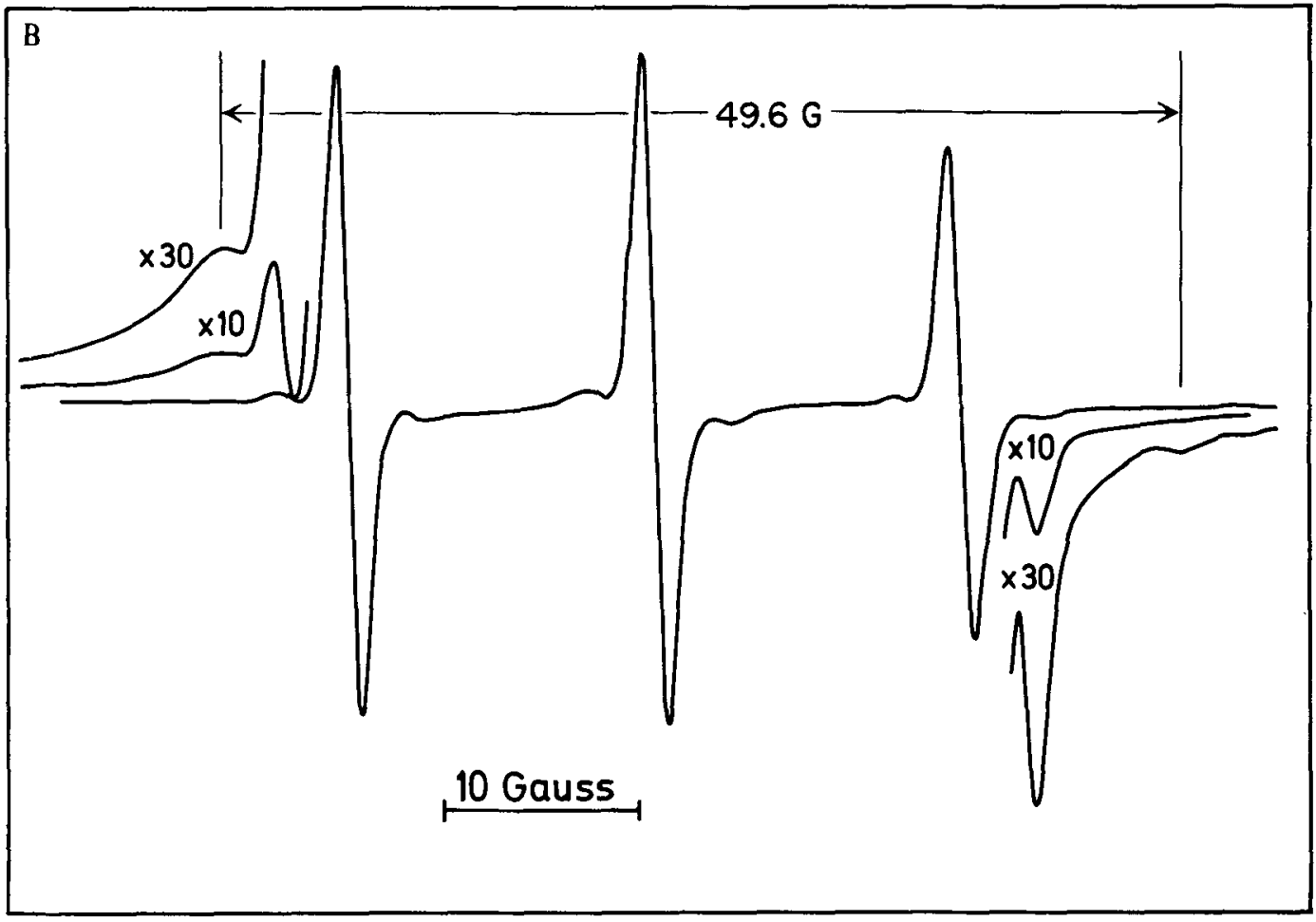


contain four single bonds around which rotations might occur. The main contributions to the motion of the nitroxide group, however, originate from rotations around the $\mathrm{C}-\mathrm{C}$ single bond connecting the pyrroline ring to the amide group, since only restricted motions around the remaining three single bonds are possible. Rotations around the $\mathrm{C}--\mathrm{N}$ single bond connecting the phenyl group to the amide group are prevented by the amide hydrogen and the two neighbouring aromatic hydrogens. Similarly, rotations around the $\mathrm{O}--\mathrm{C}$ single bond connecting the phenyl group and the glucoside are prevented by the aromatic hydrogens and hydrogen-l of the glucopyranose ring. In the hapten spin label molecule [II], rotation around this bond is further restricted by the bulky pyrroline ring. Rotation around the other part of the glucoside bond is likely to be very limited, since it will bring the hydrophobic phenyl ring close to the hydrophilic glucopyranose ring. Thus we might consider the NAG-phenyl-amide part of the spin label hapten molecules as a fairly rigid structure. Therefore we have assumed that the NAGphenyl part of the structure is the same for both I and II. The structure of the 2, 2, 5, 5tetramethyl-3-pyrroline-1-oxyl ring is planar (8) and so this ring is rotating around an axis perpendicular to the $z$-axis of the molecular Carthesian coordinate system. In this particular case we can calculate the value of the splitting constants, when the rotational axis is either parallel or perpendicular to the magnetic field. (6). These values are obtained from the formula

$$
\begin{aligned}
& A_{\|}=A_{x x} \cdot \sin ^{2} 90^{\circ}+A_{z z} \cdot \cos ^{2} 90^{\circ}=6 \mathrm{G} \\
& A_{\perp}=A_{x x}\left(1+\cos ^{2} 90^{\circ}\right)+A_{z z} \cdot \sin ^{2} 90^{\circ}=19 \mathrm{G}
\end{aligned}
$$

The spectra of the haptens I and II (Figures $2 A$ and $B$ ) obtained in the presence of the Fab fragment clearly indicate that the motion of the spin labels are anisotropic, and thus the spectra obtained are characteristic of spin labels bound to the antibody combining site. The half values of the outer splitting measured from the spectra of hapten I and II, when bound to the Fab fragment are $20.2 \mathrm{G}$ and $24.8 \mathrm{G}$, respectively, (Figure $2 \mathrm{~A}$ and $\mathrm{B}$ ). The splitting of the bound spin label $I$ is very close to the value expected for the case when the pyrroline ring rotates freely around an axis perpendicular to the nitroxide z-axis (see equations above). This suggests that the pyrroline ring is freely rotating when the hapten spin label molecule is bound to the NAG-binding antibody combining site. In case of spin label hapten II the outer splitting is much greater than expected for a freely rotating pyrroline ring. This implies that the motion of the pyrroline ring of the molecule II is highly anisotropic and in this case is in close contact with the protein molecule at the antibody site.

The natural antigen for the examined antibodies is a cell wall polysaccharide build up from $\mathrm{N}$-acetyl-glucosamine and rhamnose residues (7). N-acetyl-glucosamine is the immunogenic residue of this polymer and is bound as the head residue to a branched rhamnose polymer. In this polysaccharide $\mathrm{N}$-acetylglucosamine is always a neighbour to a rhamnose residue. The observation that the pyrroline ring of compound I can rotate freely in the antibody combining site suggests that the site cannot contain more than two glucopyranose rings. A tentative assumption would therefore be that the rhamnose residue next to the $\mathrm{N}$-acetyl-glucosamine residue is also bound in the antibody combining site. The finding that the pyrroline ring of compound II cannot rotate freely in the antibody combining site suggests that the structure of the combining site is too narrow to accomodate a benzene ring with bulky substituents at the ortho positions. This is consistent with the assumption discussed above that the combining site is built up to envelop two glucopyranose rings. The finding that hapten II has lower association binding constant than hapten $I$ in binding reactions with the antibodies support this assumption (see next section).

\subsection{Antagonism between hapten and Gd(III)}

The well separated lines of the bound and free spin label (see for example peaks $a$ and $b$ in Figure $2 \mathrm{~A}$ ) provide an excellent situation for measuring the concentration of free spin labels in equilibrium mixtures of Fab fragments and hapten. Thus from the total concentration of 


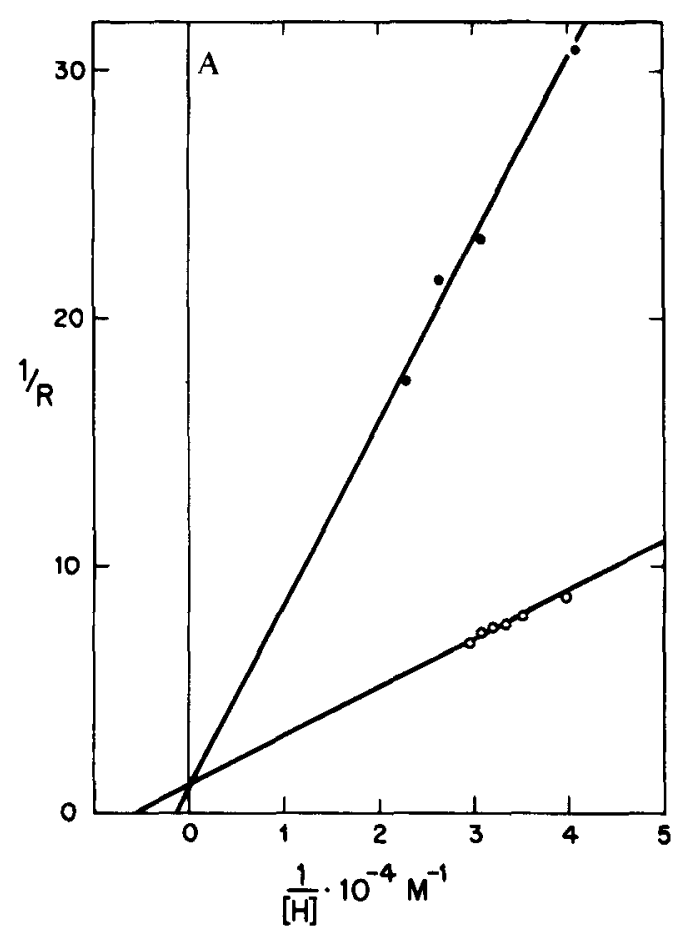

Figure 3. Binding plots of the haptens 1 and II. A) Binding of hapten I (open circles) and of hapten II (closed circles) to Fab fragments of serum 4450, l/R vs $\mathrm{I} / \mathrm{H}$. B) Binding of hapten $\mathrm{I}$ and II to Fab fragments of serum 4448 , symbols as in $A$ ), $1 / \mathrm{H}_{0}-[\mathrm{H}]$ vs $1 / \mathrm{A}_{0} ; 0 . .01 \mathrm{M}$-MES, $0.15 \mathrm{M}-\mathrm{NaCl}$, pH 6.79 .

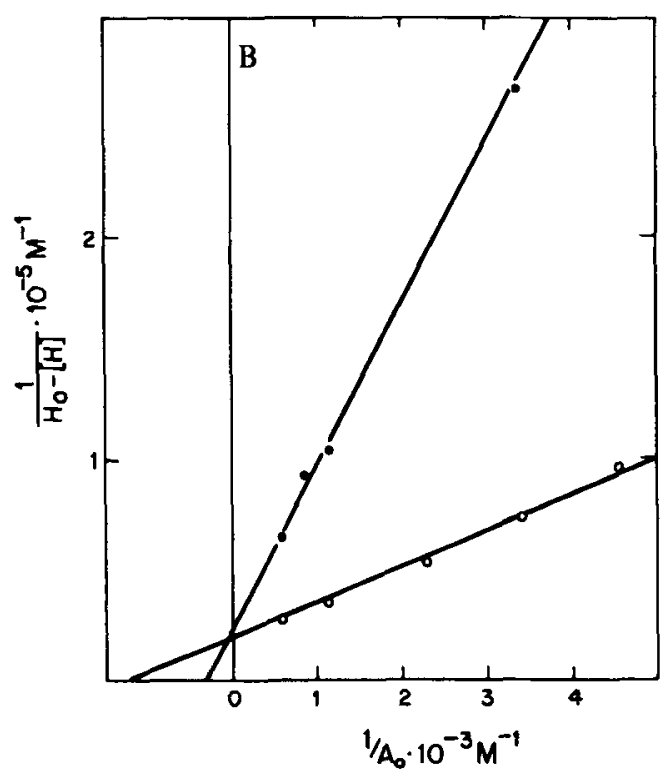

spin label hapten and of antibody the binding constant $K_{H}$ (see appendix) is readily determined from measurements of the free spin label concentrations. From titrations in which the antibody concentrations were gradually decreased from $250 \mu \mathrm{M}$ to $100 \mu \mathrm{M}$ and the concentrations of spin label were kept constant at $50 \mu \mathrm{M}$, the binding constant of the spin label haptens I and II were obtained by plotting I/R versus $1 / \mathrm{H}$ (Figure $3 \mathrm{~A}$ ) where $\mathrm{R}$ is the fraction of antibody complexes compared to the total amount of antibody and $\mathrm{H}$ is the concentration of free spin label (see appendix). From such a plot the binding constant $\mathrm{K}_{H}$ is obtained from the intercept on the abcissa as well as from the slope of the line (see appendix). The intercept on the ordinate axis is the number of antibody combining sites per mole of antibody. As an alternative graphical method the results of the titrations can be plotted in a double reciprocal plot of $\frac{1}{\left(\mathrm{H}_{\mathrm{o}}-[\mathrm{H}]\right)}$ and $\frac{1}{\mathrm{~A}_{\mathrm{o}}}$ (see appendix). In Figure $3 \mathrm{~B}$ are shown such plots representing

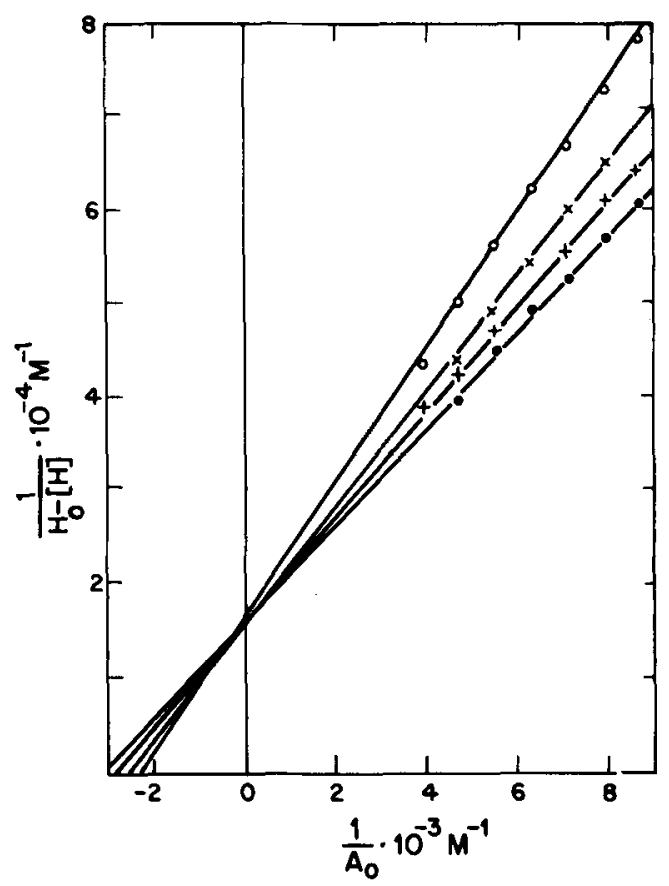

Figure 4. Binding plot of hapten I to Fab-fragment 4450 in the presence of $\operatorname{Gd}(I I I) .(\Delta)$, no $G d(I H),(+)$, $0.5 \mathrm{mM} \mathrm{GdCl}_{3},(\times), 1.0 \mathrm{~mm} \mathrm{GdCl},(0), 2.0 \mathrm{~mm}$ $\mathrm{GdCl} 1_{3}$, in all titrations, the hapten concentration was $50 \mu \mathrm{M}, 0.001 \mathrm{M}-\mathrm{MES}, 0.15 \mathrm{M}-\mathrm{NaCl}, \mathrm{pH} 6.79$. 
titrations of two antibody Fab fragment populations with the spin label haptens I and II, respectively. The results shown in Figure 4 were obtained from titrations performed in the presence of $\mathrm{Gd}(\mathrm{III})$. With increasing concentrations of $\mathrm{Gd}(\mathrm{III})$ the slopes of the straight lines are increasing, indicating mutual interactions between the binding of hapten and of Gd(III) at the combining site of the Fab fragments. As described in the appendix this pattern of interaction would indicate either an antagonism between the binding of the two molecules, or in the limiting case competition by which binding of one of the species completely prevents binding of the other. In the appendix is described a graphical method which distinguishes between these two types of competition mechanisms. It is shown that a plot of $V$

$$
V=\frac{1}{\left(\frac{A_{0}}{H_{o}-[H]}-1\right)[H]} \quad \text { (see appendix) }
$$

as a function of $1 /[\mathrm{M}]$, where $[\mathrm{M}]$ is the free concentration of $\mathrm{Gd}(\mathrm{III})$, for large values of $[\mathrm{M}]$ is a linear function with an intercept on the ordinate equal to $\mathrm{K}_{\mathrm{MH}}$ (see appendix) and a slope of $\left(K_{H}-K_{M H}\right) / K_{M}$. In the limiting case where $\mathrm{K}_{\mathrm{MH}}$ is zero the line will go through the origin and have a slope of $\mathrm{K}_{\mathrm{H}} / \mathrm{K}_{\mathrm{M}}$. Thus from a plot of this type a distinction between the two types of competition mechanisms is possible. In case of an antagonistic mechanism $K_{H}$ is determined from the $\mathrm{x}$-axis intercept in Figure

\section{Table I}

The binding constants and the antagonistic binding constants of the binding of antibodies to hapten and Gd (III) $)^{1)}$

\begin{tabular}{c|c|c|c|c|c}
\hline Serum & Hapten & $\mathrm{K}_{\mathrm{H}^{\mathrm{M}-1}}$ & $\mathrm{~K}_{\mathbf{M}^{\mathrm{M}-1}}$ & $\mathrm{~K}_{\mathrm{MH}^{\mathrm{M}-1}}$ & $\mathrm{~K}_{\mathrm{HM}}{ }^{\mathrm{M}-1}$ \\
\hline 4448 & I & 1000 & & & \\
4448 & II & 250 & $6.5 \times 10^{4}$ & 112 & $2.9 \times 10^{4}$ \\
4450 & I & 3700 & $3.4 \times 10^{3}$ & 271 & $2.6 \times 10^{4}$ \\
4450 & II & 1000 & & & \\
\hline
\end{tabular}

1) The data given were all obtained from plots of $\left(\mathrm{H}_{\mathrm{O}}\right.$ - [H]) vs $1 / A_{0}$. For comparison the data of 4450 , from plots of $1 / R$ vs. $I / H$ were for $I$ and $I 1,5500 \mathrm{M}^{-1}$ and $1500 \mathrm{M}^{-1}$, respectively.
$3 \mathrm{~A}$, and $\mathrm{K}_{\mathrm{MH}}$ is obtained as described above. $\mathrm{K}_{\mathrm{M}}$ is readily calculated from the slope of the $\mathrm{V}$ vs. $1 /[\mathrm{M}]$ plot and from the binding constant correlation, $\mathrm{K}_{\mathrm{HM}}$ can be calculated. Figure 5 shows an example of plotting $V$ versus the reciprocal of the $\mathrm{Gd}(\mathrm{III})$ concentration. The

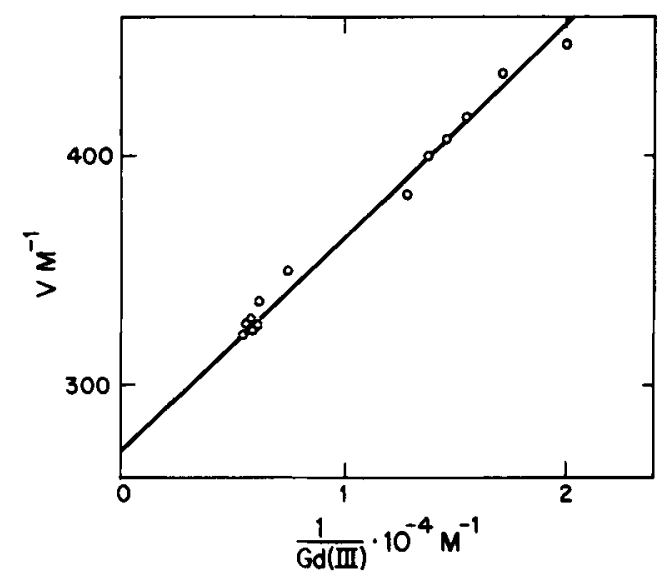

Figure 5. A graphical analysis to distinguish between binding site interactions modes. Since the line has a $y$ axis intercept different from the origin, the mutual binding of hapten and metal is defined by a $\mathrm{K}_{\mathrm{MH}}$ value (see Appendix).

resulting binding constants are given in Table $\mathrm{I}$.

The binding of the two haptens I and II to the Fab fragments of antibody populations from the sera 4448 and 4450 was examined. The data show that the Fab fragments of 4450 bind the haptens slightly stronger than those of 4448 . We notice that hapten $I$ in both of the antibody populations is bound by a factor of four stronger than hapten II. The binding of Gd(III) to the two antibody populations is also seen to be different. However, the binding constants obtained are of the same order of magnitude as those determined for normal rabbit IgG (1), and also very similar to the values measured for the binding of $\mathrm{Gd}(\mathrm{III})$ to the $\mathrm{Fv}$ fragment of the mouse myeloma protein MOPC-315, (2). The antagonistic effect of $\mathrm{Gd}(\mathrm{III})$ on the binding of the hapten I has a magnitude of about 13, $\left(\frac{\mathrm{K}_{\mathrm{H}}}{\mathrm{K}_{\mathrm{MH}}}\right)$, Table 1, whereas in the case of hapten II this factor is only 2. So the effect of Gd(III) on the 
binding of hapten II is much smaller than that of hapten 1 .

DWEK et al. have shown that in the MOPC$315 \mathrm{FV}$ fragment the antagonistic effect of $\mathrm{Gd}(\mathrm{III})$ on the hapten binding originates from the existence of two different conformations of the combining site (2): one which favours the binding of hapten, and one which favours the binding of $\mathrm{Gd}(\mathrm{III})$. The lower antagonistic effect of $\mathrm{Gd}(\mathrm{III})$ on the binding of hapten II might be due to a looser binding of this hapten as indicated by its lower binding constant, since a loose mode of binding might be expected to be less sensitive to a change of conformation induced by Gd(III).

\section{CONCLUSION}

In this work we have applied spin labeled haptens as probes for the antibody combining site of antibodies against a cell wall polysaccharide of group A Streptococci. The spin labels have been built up to have structures similar to the original antigen. They contain an $\mathrm{N}$-acetyl-glucosamine residue which is the immunogenic residue of the polysaccharide. A phenyl group has been attached in order to imitate the pyranose ring next to the $\mathrm{N}$-acetyl glucosamine in the polysaccharide antigen. A spin label of the 2, 2, 5, 5-pyrroline type has been coupled to the phenyl group either in the para or ortho position to the glucoside bond. In the first case the spin label ring would imitate a second pyranose ring of the polysaccharide. In the second case the molecule has an odd structure as compared to the original antigen. Measurements of the binding constants for these two compounds have demonstrated that the combining site indeed has a much lower affinity for this "odd" spin labeled hapten than for the more "regular" one. E.s.r. studies of this molecule (hapten II) shows that the spin label ring is strongly immobilized when the NAG part of the molecule is anchored in the combining site. The para substituted NAG-phenyl spin labeled hapten seems to be bound in the combining site in a mode which allows the spin label ring to rotate freely. All together these observations suggest that the combining site of the examined antibodies has a structure which has just the right size to contain the outer two glucopyranose rings of the polysaccharide antigen.

This work has further demonstrated that the anti Streptococcus group $\mathrm{A}$ antibodies, like the myeloma protein MOPC-315, binds hapten and $\mathrm{Gd}(\mathrm{III})$ in an antagonistic fashion. The antibodies examined in the present study were antigenically induced and so are naturally elicited antibodies, and the phenomenon might therefore be a general property of antibodies. Only two examples of this, from a biological point of view rather odd behaviour of antibody combining sites, have so far been described; hence, it can be hazardous to generalize these findings. However, with respect to the great differences between the two systems, and to the findings of DWEK et al. that normal rabbit IgG contains six binding sites for $\mathrm{Gd}(\mathrm{III})$ (1), it seems quite possible that the described antagonism between hapten and $\mathrm{Gd}(\mathrm{III})$ is a general property of antibody combining sites, reflecting a common structural feature of $\mathrm{Fv}$ fragtments of antibodies.

\section{REFERENCES}

1. Dower, S. K., R. A. Dwek, A. C. Mclaughlin, L. E. Mole, E. M. Press \& C. A. Sunderland: The binding of lanthanides to non-immune rabbit immunoglobulin $G$ and its fragments. Biochem. J., 149, 73-82 (1975)

2. Dwek, R. A., D. Givol, R. Jones, A. C. Mclaughlin, S. Wain-Hobson, A. I. White \& C. WRIGHT: Interactions of the lanthanide and hapten binding site in Fv-fragment from the myeloma protein MOPC 315 Biochem. J., 155, $37-53(1976)$

3. Horton, D.: 2-acetamido-3, 4, 5-tri-O-acetyl-2deoxy-glucopyranosyl chloride. In: E. J. Corey, ed.: Organic Synthesis, John Wiley and Sons, 46, $1-4,(1966)$

4. Hsia, J. C. \& L. H. Piette: Spin-labelling as a general method in studying antibody active sites. Arch. Biochem. Biophys., 128, 296-307 (1969)

5. Hubbel, W. L. \& H. M. McConnell: Molecular motion in spin-labeled phospholipids and membranes. J. Am. Chem. Soc., 93, 314-326 (1971)

6. Jost, P., A. S. Waggoner \& D. H. Griffith: Spin labelling and membrane structure. In: 
Structure and Function of biological membranes, ed. L. I. Rothfield, Academic Press, 83-144 (1971)

7. Krause, R. M. \& M. McCarthy: Studies on the chemical structure of the streptococcal cell wall. J. Exp. Med. 115, 49-62 (1962)

8. Kruger, G. J. \& J. C. A. Boeyens: The crystal and molecular structure of the potassium salt of 2, 2, 5, 5-tetramethyl-3-carboxy-pyrroline-1-oxyl. Proc. Nat. Acad. Sci. USA, 61, 422-428 (1968)

9. LEABACK D. H. \& P. G. WALKER: The preparation and properties of acetochloroglucoseamine and its use in the synthesis of 2-acetamido-2deoxy- $\beta$-D-glucosides. J. Chem. Soc. 60, 47944760 (1957)

10. PORTER, R. R.: The hydrolysis of rabbit $\gamma$ globulin and antibodies with crystalline papain. Biochem. J., 73, 119-127 (1959)

11. Poulsen, F. M. \& J. T. Johansen: Purification of anti Streptococcus group $A$ antibodies by affinity chromatography and isoelectric focusing. Carlsberg Res. Commun. 42, - (1977)

12. Rozantzev, E. G. Free nitroxyl radicals, Plenum Press, New York and London (1970)

13. Stryer, L. \& O. H. Griffith: A spin labelled hapten. Proc. Nat. Acad. Sci. USA, 54, 1785-1791 (1965)

14. Westphal, O. \& H. SChmidt: N-Acetylglucosamine als determinante gruppe in künstlichen Antigene, Ann. Chem., 575, 84-90 (1952)

\section{APPENDIX}

\section{Scheme I}

$$
\begin{aligned}
& \mathrm{A}+\mathrm{H} \rightleftharpoons \mathrm{AH} \quad(\mathrm{I}) \\
& \mathrm{A}+\mathrm{M} \rightleftharpoons \mathrm{AM} \quad(\mathrm{II}) \\
& \mathrm{AH}+\mathrm{M} \rightleftharpoons \mathrm{AMH}(\mathrm{III}) \\
& \mathrm{AM}+\mathrm{H} \rightleftharpoons \mathrm{AMH}(\mathrm{IV}) \\
& \mathrm{K}_{\mathrm{H}}=\frac{[\mathrm{AMH}]}{[\mathrm{A}][\mathrm{H}]} \\
& \mathrm{K}_{\mathrm{M}}=\frac{[\mathrm{AM}]}{[\mathrm{A}] \cdot[\mathrm{M}]} \\
& \mathrm{K}_{\mathrm{MH}}=\frac{[\mathrm{AMH}]}{[\mathrm{AM}] \cdot[\mathrm{H}]} \\
& \mathrm{K}_{\mathrm{HM}}=\frac{[\mathrm{AMH}]}{[\mathrm{AH}][\mathrm{M}]}
\end{aligned}
$$

A is antibody, $\mathrm{H}$ is hapten, $\mathrm{M}$ is $\mathrm{Gd}(\mathrm{III})$
In scheme I, A symbolizes the Fab fragment of anti Streptococcus group A antibodies, M symbolizes $\mathrm{Gd}(\mathrm{III})$ and $H$ the hapten spin label, $\mathrm{AH}, \mathrm{AM}$, and $\mathrm{AMH}$ are the complexes possibly formed by the species $A, M$, and $H$. The binding constants $\mathrm{K}_{\mathrm{H}}, \mathrm{K}_{\mathrm{M}}, \mathrm{K}_{\mathrm{HM}}$, and $\mathrm{K}_{\mathrm{MH}}$ are defined in the scheme and we note that these are correlated in case all four equilibria are established simultaneously by the equation $\mathrm{K}_{\mathrm{H}} \mathrm{K}_{\mathrm{HM}}=\mathrm{K}_{\mathrm{M}} \mathrm{K}_{\mathrm{MH}}$.

In the absence of $M$ we consider only the equilibrium I (see scheme I) and the function

$\frac{1}{\mathrm{R}}=\frac{1}{[\mathrm{H}]} \cdot \frac{1}{\mathrm{nK}_{\mathrm{H}}}+\frac{1}{\mathrm{n}}$

is readily elaborated. $R=\left(H_{0}-[H]\right) / A_{0}$ where $\mathrm{H}_{0}$ and $\mathrm{A}_{0}$ are the total concentration of hapten and antibody, respectively, and $\mathrm{n}$ is the fraction of Fab fragments forming complexes with the hapten spin labels. [1] is a straight line function in $1 / R$ and $1 /[H]$, from which $K_{H}$ is obtained from the intercept on the $\mathrm{x}$-axis and from the slope of the line. The intercept on the $y$-axis is the reversible number of binding sites per mole of Fab fragments. Since this graphical method might amplify small errors of the experimental data we have compared the results with those obtained from an alternative method. From the conservation equation it is readily seen that

$$
H_{o}-[H]=H_{o} \cdot \frac{K_{H}[A]}{1+K_{H}[A]}
$$

which means that a double reciprocal plot of $\left(\mathrm{H}_{0}-[\mathrm{H}]\right)$ and $[\mathrm{A}]$ is a linear function. Since [A] is unknown we might express [A] as a function of $[\mathrm{H}]$ and $\mathrm{A}_{0}$ :

$$
[A]=\frac{A_{o}}{1+K_{H}[H]}
$$

By introducing [3] in [2] a rather complicated expression is obtained. However, $[\mathrm{H}]$ is approximately linear in $A_{0}$ within the concentration interval considered so the empirically found expression

$$
[\mathrm{H}]=\alpha \cdot \mathrm{A}_{\mathrm{o}}+\beta
$$

can be introduced to give

$$
\frac{1}{H_{o}-[H]}=\frac{1}{A_{o}} \cdot \frac{K_{H} \cdot \beta+1}{H_{o} K_{H}}+\frac{1+\alpha}{H_{o}}
$$


[5] is a linear function of $\left(\mathrm{H}_{0}-[\mathrm{H}]\right)^{-1}$ in $\left(\mathrm{A}_{0}\right)^{-1}$ and $K_{H}$ is readily obtained from the intercept on the $\mathrm{x}$-axis which is

$-\frac{1+\alpha}{1+K_{H} \cdot \beta} K_{H}$

The values of $\alpha$ and $\beta$ are measured from the slope and the $y$-axis intercept respectively, of linear plots of the free spin label concentration [H] versus $A_{0}$ from eqn. [4].

In the presence of metal we have to consider the following mechanisms, one in which only the equilibria I and II are formed (see scheme I), and one in which all four are formed. In the last case a function similar to [1] can be elaborated and it is found that the intercept on the $\mathrm{x}$-axis is

$K_{A}=-\frac{K_{H}+K_{M} \cdot K_{M H}[M]}{1+K_{M} \cdot[M]}$

and that the function is a straight line if $[M]$ is constant. Similarily the first case is described by a straight line function with an intercept on the $\mathrm{x}$-axis equal to

$$
-\frac{\mathrm{K}_{\mathrm{H}}}{1+\mathrm{K}_{\mathrm{M}}[\mathrm{M}]}
$$

However, a graphical analysis of either of these types would not distinguish between the two types of competition possible in this system. The following analysis was therefore made in order to distinguish between these competition modes. From the conservation equations the following expressions are obtained

$$
[\mathrm{H}]=\frac{\mathrm{H}_{\mathrm{o}}}{1+\mathrm{K}_{\mathrm{H}}[\mathrm{A}]+\mathrm{K}_{\mathrm{M}} \cdot \mathrm{K}_{\mathrm{MH}}[\mathrm{A}][\mathrm{M}]}
$$

$$
[\mathrm{A}]=\frac{\mathrm{A}_{\mathrm{o}}}{1+\mathrm{K}_{\mathrm{H}}[\mathrm{H}]+\mathrm{K}_{\mathrm{M}}[\mathrm{M}]+\mathrm{K}_{\mathrm{M}} \cdot \mathrm{K}_{\mathrm{MH}}[\mathrm{H}][\mathrm{M}]}
$$

rearrangement of equation [9] leads to

$$
\frac{[\mathrm{H}]}{\mathrm{H}_{\mathrm{o}}-[\mathrm{H}]}=\frac{1}{[\mathrm{~A}]\left(\mathrm{K}_{\mathrm{H}}+\mathrm{K}_{\mathrm{M}} \mathrm{K}_{\mathrm{MH}}[\mathrm{M}]\right)}
$$

by introducing equation [10] into [11] we obtain

$$
\frac{[\mathrm{H}]}{\mathrm{H}_{\mathrm{o}}-[\mathrm{H}]}=\frac{1+\mathrm{K}_{\mathrm{M}}[\mathrm{M}]+[\mathrm{H}]\left(\mathrm{K}_{\mathrm{H}}+\mathrm{K}_{\mathrm{M}} \mathrm{K}_{\mathrm{MH}}[\mathrm{M}]\right)}{\mathrm{A}_{\mathrm{o}}\left(\mathrm{K}_{\mathrm{H}}+\mathrm{K}_{\mathrm{M}} \mathrm{K}_{\mathrm{MH}}[\mathrm{M}]\right)}
$$

which is rearranged to

$\frac{1}{\left(\frac{A_{o}}{H_{o}-[H]}-1\right)[H]}=\frac{K_{H}+K_{M} \cdot K_{M H}[M]}{1+K_{M}[M]}$ [13]

The right side of this equation is readily developed into an indefinite polynomial

$$
\frac{K_{H}+K_{M} \cdot K_{M H}[M]}{1+K_{M}[M]}=K_{M H}+\frac{1}{[M]} \cdot \frac{K_{H}-K_{M H}}{K_{M}}+\frac{1}{[M]^{2}} \cdot \frac{K_{H}-K_{M H}}{K_{M}^{2}}+\ldots
$$

